\title{
Identifying trafficked migrants and refugees along the Balkan route. Exploring the boundaries of exploitation, vulnerability and risk
}

\author{
Anette Brunovskis $^{1}$ (D) $\cdot$ Rebecca Surtees $^{2}$
}

Published online: 18 May 2019

(C) The Author(s) 2019

\begin{abstract}
This article explores what we can learn about the identification of and assistance to trafficked persons from practitioners in Serbia on the front line of Europe's so-called "refugee crisis". Questions arise as to whether and to what extent the anti-trafficking framework is effective in offering protection to trafficked migrants/refugees in a mass migration setting, but also what is lost if the specific perspective of the anti-trafficking framework is set aside or given lower priority. It is important to discuss who is included and who is excluded; whether protection and assistance meet people's needs; and whether or how the existing framework can be used to greater effect. While it was challenging to operationalise the anti-trafficking framework, both conceptually and practically, during the "refugee crisis" in the Balkans, it remains an important approach that should have been mobilised to a greater extent, both to secure individual protections and rights and to gather information about human trafficking in conflict and crisis, which, in turn, increases the ability to respond effectively.
\end{abstract}

\section{Introduction}

In this article we discuss what we learned about the identification of and assistance to trafficked persons from NGO staff in Serbia on the front line of Europe's so-called "refugee crisis". Beginning in 2015, large numbers of migrants/refugees crossed through the Balkans, with numbers peaking that year, but remaining high in 2016. Serbia's geographical location - as a non-European Union member bordering the European Union (EU) countries of Croatia and Hungary to the west and north - was

Anette Brunovskis

Anette.Brunovskis@fafo.no

Rebecca Surtees

rsurtees@nexusinstitute.net

1 Fafo, P.O. Box 2947 Toyen, NO-0608 Oslo, Norway

2 NEXUS Institute, 1440 G Street NW, Washington, D.C 20005, USA 
on the route used by many migrants/refugees seeking to reach Western and Northern European countries, particularly Germany and Sweden. In this context, the antitrafficking framework ${ }^{1}$ came under considerable pressure, both conceptually and practically.

Conceptually, distinguishing particular forms of vulnerability and exploitation that could constitute human trafficking was complicated in a context where vulnerability was the norm, individual migration trajectories were complex and forms of exploitation often differed from established human trafficking patterns in the region. Gendered assumptions about vulnerability also influenced the identification (and nonidentification) of trafficking victims amongst migrants/refugees. Practically, identification of and assistance to trafficking victims was difficult because of the large number of people passing through the Balkans in a short period of time and interactions with migrants/refugees were often brief and constrained by issues of language and trust. Moreover, identification as a trafficking victim was, in many cases, against the selfdefined interests of migrants/refugees as involvement in investigations or prosecutions while en route or receiving a temporary residence permit and assistance in Serbia interfered with their goal of reaching and claiming asylum in their destination in the EU.

In this article, we discuss these dynamics and constraints, particularly in terms of what this means for an understanding and the implementation of a human trafficking response in a mass migration situation. An important question is whether and to what extent the anti-trafficking framework is effective in offering protection to migrants and refugees in a mass migration setting, particularly while in transit, or whether other instruments and protections are better suited to meeting these needs. Equally important is to consider what is lost if the anti-trafficking lens and framework is set aside or given lower priority, which, to a large extent, seems to have been the case along the Balkan route during the "refugee crisis".

Migration flows along the eastern and central Mediterranean migration routes have diminished considerably, particularly as a result of agreements on migration control between the EU and Turkey, Libya and Niger. However, the "Balkan route" continues to operate, albeit with fewer migrants/refugees. With strict EU border controls and many of the migrants/refugees having exhausted their financial resources, vulnerability to exploitation and human trafficking may be amplified in transit settings. As such, the issues of migration, vulnerability and the identification and protection of trafficking victims along the Balkan route continue to be highly relevant, despite diminishing media and political attention, and moreover to draw lessons for any such situations in the future.

In this article, we first discuss the complexities in terminology around migrants, refugees and trafficking victims as well as understandings of vulnerability that arise in different migration pathways. We then outline some of the trafficking patterns that

\footnotetext{
${ }^{1}$ The anti-trafficking framework refers to the generally agreed framework to combat human trafficking. The Three-P Paradigm is a framework used by governments around the world to combat human trafficking. It is outlined in the United States' Trafficking Victims Protection Act (TVPA) and in the United Nations' Protocol to Prevent, Suppress and Punish Trafficking in Persons, Especially Women and Children, supplementing the United Nations Convention Against Transnational Organized Crime (commonly referred to as the Trafficking Protocol). The paradigm was elaborated by the United States government in 1998 in accordance with efforts to combat violence against women and trafficking in women and girls (see e.g. [36]). The protection framework refers to the identification, referral and assistance of trafficking victims, toward their long term recovery and reintegration.
} 
social workers/frontline staff identified among migrants/refugees in Serbia in 2015 and 2016. The paper then describes the main barriers to identification and assistance of trafficking victims in a mass migration/transit setting, before discussing the implications of our findings.

\section{Approach and data}

This article is based on data collected in the project Ttrafficking vulnerabilities and risk factors ${ }^{2}$ in which we worked closely with the two Serbian NGOs Atina and Center for Youth Integration (Centar za Integraciju Mladih; CIM). Both organizations work on identification, assistance and long-term reintegration of trafficking victims in Serbia, providing comprehensive services through transition housing programmes, day centres and field support teams. During fieldwork in Serbia in October 2016, case data collected by Atina and CIM were shared with us in anonymised form, according to ethical protocols with respect to confidentiality, anonymity and privacy. Each case was reviewed and then discussed with the relevant case worker involved in identifying and assisting the individual. We also conducted interviews with nine frontline staff about these specific cases, to identify issues in their efforts to identify migrants/refugees as potential victims of trafficking as well as broader challenges that they faced in their efforts to protect migrants, refugees and trafficking victims. We then went on to code the data, identifying different categories of human trafficking cases documented and assisted by the NGOs within the migrant/refugee population and analysed these cases in terms of barriers to and opportunities for identification and assistance. Our analysis is based on information about 32 cases representing different patterns and experiences of human trafficking amongst migrants/refugees in Serbia as well as different challenges faced in the identification and assistance of these trafficking victims.

\section{The Balkan route and the "refugee crisis" in Serbia}

The "Balkan route" refers to the path stretching from the Middle East to the European Union through Turkey and South-East Europe, via the well-documented and sometimes deadly journeys by sea from Turkey to Greece, overland to Macedonia or Bulgaria and onward to the European Union, either via Serbia and Hungary or Serbia, Croatia and Slovenia [6].

In 2015, there was a drastic increase in the numbers of migrants and refugees crossing into Macedonia and Serbia from Turkey and Greece and, to a lesser extent, from Bulgaria. The United Nations High Commissioner for Refugees (UNHCR) estimated that more than half a million people entered Serbia between October 2015 and September 2016 [46], the vast majority passing through Serbia on their way to other countries. Serbian government sources stated that the number was as high as 900,000 over the course of the "crisis" [40]. Migrants/refugees primarily originated from Syria, Iraq and Afghanistan [22].

\footnotetext{
${ }^{2}$ Trafficking Vulnerabilities and Risk Factors was funded by the Norwegian Ministry of Foreign Affairs and resulted in the report Vulnerability and exploitation along the Balkan route: Identifying victims of human trafficking in Serbia which presents a practice oriented analysis of trafficking patterns among refugees in the Balkans as well as applicable recommendations for identification work in this population [10].
} 
Countries in the West Balkans initially kept their borders open, allowing migrants/ refugees to travel onward to the European Union. But, by September 2015, Hungary had built a wall along its southern borders with Serbia and Croatia to block further migrant/ refugee crossings. And on October 16, 2015, Hungary officially closed its border crossing with Serbia [43]. At the time of our fieldwork in late October 2016, NGOs reported that Hungary allowed only 20 migrants/refugees to cross into Hungary per day (Deutsche [18]) and only those from "priority refugee countries" (i.e. Syria, Iraq and Afghanistan).

In November 2017, UNHCR reported that there were 4326 new refugees, asylum seekers and migrants in Serbia. While there were 643 new arrivals that month, only 15 individuals sought asylum, suggesting that the vast majority do not plan to stay in Serbia but will try to follow the Balkan route further north and into the European Union [45].

\section{Migration, vulnerability and protection - Policy and terminology challenges}

There are discussions on whether existing policy and terminology sufficiently capture and address the complex context of migrant/refugee flows into Europe, where migration streams are often described as "mixed" - that is, heterogeneous and consisting of people with different statuses, motivations, history and experience all travelling in the same directions and by the same means [13]. Debate has emerged as to the appropriateness of categorizing individuals as either refugees or (economic) migrants, given that only the former categorization translates into protection opportunities [16]. Moreover, in categorisations of migrants/refugees, vulnerability is often understood in a limited sense, with some groups more likely to be recognised as vulnerable (e.g. children, single women, women traveling with children) than others (e.g. men and older boys) [32], or indeed vulnerability of men and boys to human trafficking generally.

Much terminology in the migration field is contested and used for different (political) purposes, as is the case with "human trafficking". In discussions of, and actions on, the handling of the migrant/refugee situation, particularly in the Mediterranean in 2015 and 2016, there was widespread conflation of human trafficking and human smuggling, with the latter frequently referred to as human trafficking, as noted in media comments at the time (Deutsche [17, 30, 37]). The human trafficking term was often used imprecisely in referring to all movement of people across the Mediterranean, rather than the, in many cases, more appropriate framing of "human smuggling" or the more neutral "facilitation". It is also worth noting that the political rhetoric of smugglers-as-traffickers has not translated into corresponding protective measures for what would logically, as a consequence of this understanding, be assumed to be a massive number of trafficking victims arriving in Europe.

Conceptual clarity is important in efforts to understand this issue and we take, as a starting point, the definition of human trafficking in the United Nations Protocol to Prevent, Suppress and Punish Trafficking in Persons [47], article 3. ${ }^{3}$ Nonetheless, a

\footnotetext{
3 Trafficking in persons is the recruitment, transportation, transfer, harboring or receipt of persons, by means of the threat or use of force or other forms of coercion, of abduction, of fraud, of deception, of the abuse of power or of a position of vulnerability or of the giving or receiving of payments or benefits to achieve the consent of a person having control over another person, for the purpose of exploitation.
} 
dilemma in research in this field is to what extent using legal and policy terms as a starting point for inquiry closes off our understanding and ability to recognise the complexities of people's lives beyond whether or not they fit into a particular legal or administrative category. This is highly relevant in the identification of trafficking victims, not least since it can determine access or non-access to certain rights and protections. In discussing research on forced migration, Bakewell maintains that if researchers adopt policy makers' categories, concepts and priorities, this privileges policy makers' world view and risks rendering large groups of forced migrants invisible both in research and policy making. He calls for more policy irrelevant research, to challenge taken-for-granted assumptions that underpin practice, to bring about significant change in the lives of forced migrants [5]. Similarly, others argue that while labelling is needed for migration management, migration scholars must move beyond these clear cut categories to better understand and analyse migration decisions and experiences [19].

These observations point to the necessity of recognising real-life complexities and the often considerable divergence between administrative categories and people's own accounts of their experiences as well as their own perception of what will (or will not) benefit them. This is of great relevance in human trafficking research as anti-trafficking policy has, in many contexts, been criticised for poorly corresponding to peoples' lived experiences [3, 39, 49]. And in our past research we have also found that the "trafficking victim" category is sometimes perceived as imposed and irrelevant for those to whom it is applied [8]. But we also contend that an important part of trafficking research, and not least research that aims to contribute to positive change within the current practice and policy landscape, is to consider whether and to what extent existing protection regimes are utilised and/or useful. The anti-trafficking framework is one such protection regime with individual rights attached to victims who are formally identified as trafficked. This does involve taking, as a starting point for our research, the administrative labels (or policy terms) used to distinguish different categories of migrants and examine the process through which these labels are applied.

However, the use of administrative and legal categories does not mean that these categories need to go unquestioned. While Bakewell's call for policy irrelevant research and moving beyond policy categories is compelling, we see as an equally important goal to conduct policy relevant critical research. In our case, this has meant analysing the challenges involved in applying the policy framework of anti-trafficking in a transit setting, what forms of human trafficking were identified and what were options and limitations in available assistance. As we will return to in the discussion, these categorisations are not unproblematic nor are they seen as such by those who use them in their daily work. Continued discussion is needed about who is included, who is excluded, whether protection and assistance meet people's needs and whether or how this existing anti-trafficking framework can be used to greater effect at different stages of an individual's migration or flight.

Our goal with this research is to communicate and inform the practice and understanding both of policy makers and practitioners in the field. As such, we choose to use the hybrid designation "migrant/refugee" when referring to people moving along the Balkan route. This approach seeks to recognise important discussions about terminology that ensued after news outlet Al Jazeera announced that it would no longer use the term "Mediterranean migrants", but instead refer to "refugees" when reporting on those crossing the sea. This decision was a reaction to "Mediterranean migrants" being 
referred to in derogatory and dehumanising terms in media and by high-ranking politicians (e.g. "hordes" [44], or "swarms" [25])[28]. Opposing voices argued that Al Jazeera's move reinforced a notion of "good refugees" and "bad migrants", implicitly condoning the perspective that the former are entitled to sympathy and support, while the latter are not, and held that "migrant" should be used as an inclusive category that also includes refugees, in line with UN recommendations on migration statistics [12, 48]. Both of these positions highlight important points and, not least, that we need to carefully consider our use of terms and concepts, especially in evolving and contested social and political contexts. Nonetheless, in terms of policy and practice on the ground, the distinction between migrant and refugee matters a great deal. "Migrant" and "refugee" are distinct legal and administrative categories that determine how agencies and institutions can and do react and the rights and opportunities afforded to migrants/ refugees. We have opted for this melded term to be inclusive of and acknowledge this broader discussion and so as not to distract from our general findings and analysis.

\section{Experiences with identification: Grey areas and conceptual challenges}

Different types of human trafficking amongst migrants/refugees were reported to frontline NGO responders to have taken place at some point during the journey,, including trafficking for sexual exploitation, labour exploitation, removal of organs, exploitation in criminal activity and forced marriage [27]. The examples presented here are not intended as a full or representative picture of trafficking cases along the Balkan route, but rather to present the variety of cases that NGO staff encountered, as well as cases where exploitation was insufficiently clear in terms of whether individuals were (or were not) trafficked.

The focus of the debate about smuggling versus trafficking in Mediterranean boat crossings has been on how those who transport people across borders are to be understood - as smugglers or as traffickers. One recent study of trafficking and smuggling along the Balkan route found that, while the overwhelming majority of migrants/refugees ( 75\%) did not report trafficking experiences, $7.9 \%$ of the sample reported engaging in labor during migration; $26.8 \%$ of the sample reported experiencing deception at the hands of smugglers; and $12.2 \%$ of the sample reported involuntary family separations caused by smugglers [29]. However, while smugglers were involved in some human trafficking cases identified in Serbia, this far from covered all human trafficking cases. Migrants/refugees also reported to have been exploited by locals along the route, by fellow migrants/refugees and by intimate partners or other family members. Thus, in a mass migration setting it is necessary to look beyond the issue of whether smugglers are "good" or "bad" and instead understand that human trafficking in this environment has its origin in the profound vulnerability created by being irregularly and expensively on the move.

Cases of trafficking for sexual exploitation were reported amongst males and females, both minors and adults. Some migrants/refugees were forced into prostitution in countries along the route. Cases of labour trafficking were reported amongst migrants/ refugees while in transit, largely when individuals needed to make money to move on. A survey of Syrian refugees along the Balkan route found that refugees crossing by boat from Turkey to Greece paid on average 33\% more following the EU - Turkey agreement 
in March 2016 [29], which involved, among other things, stepping up security efforts by the Turkish coast guard and police [20]. The same study found that accounts of labour exploitation of refugees in Turkey were more common after the agreement, ascribing this to the higher costs and risks associated with boat crossings to Greece [29].

In our data, migrants/refugees reported being trafficked for labour along the route in different fields of work (e.g. agriculture, tailoring, bakery), while having their passports seized and held by "employers", being refused pay, unable to leave the "work" situation and subjected to threats and various forms of violence. Labour trafficking had also, in some cases, led to persons becoming migrants/refugees, as in the case of one woman who escaped labour and sexual exploitation as a domestic worker in the Middle East and fled to Europe.

Less common cases included other forms of exploitation such as the removal of organs and being forcibly involved in criminal activities (e.g. assisting in smuggling operations). In addition, some women and girls were forced into marriages/ relationships that corresponded with international definitions of human trafficking. In some cases, these forced marriages were the reason for women and girls to flee; in other cases, these forced marriages took place during the journey and were a consequence of their vulnerability as a migrant/refugee.

NGO staff often encountered cases they described as being on the margins of trafficking - i.e. when people were vulnerable and/or possibly exploited - but where it was difficult for NGO staff to determine whether these were victims of human trafficking. As noted in the introduction, distinguishing particular forms of vulnerability and exploitation that could constitute human trafficking was sometimes complicated as vulnerability was all but the norm and forms of exploitation sometimes different from established and known human trafficking patterns in the region.

Survival sex was reported amongst migrants/refugees, referring to situations in which persons have been forced to exchange sexual services for subsistence needs [23] - for example, to pay for food and accommodation or to pay smugglers for the onward journey. In some cases, "survival sex" may constitute human trafficking - for example, when migrants/refugees were coercively required by traffickers to provide sexual services or when their vulnerability was exploited. Even when accommodated in refugee camps, refugees' needs cannot always be entirely met, which led some NGO staff to raise concerns that some migrants/refugees would be forced to engage in prostitution (either forced through trafficking or as a means of survival) to support themselves and their families.

Some migrants/refugees reported being raped by smugglers along the route. In some cases, this also involved extortion that may cumulatively have constituted human trafficking - for example, when smugglers isolated an individual and raped them to pressure family members (either traveling with them or in the home country) to pay money for their release and/or safe passage. This is similar to experiences reported in the Sinai Peninsula in Egypt [33, 35]. Both female and male migrants/refugees reported having been sexually assaulted as well as subjected to other forms of violence.

Not all abuses and violations within refugee settings while in transit constitute human trafficking. Many individuals were exposed to other types of violence and violations while in refugee camps and settings, including rape and physical assault. These are different and discrete violations, distinct from human trafficking. The many reports of violence and violations, including sexual and physical violence, signals the 
potential risks and general lack of safety in asylum and transit settings. Furthermore, these profound vulnerabilities also highlight the shortcomings of the humanitarian protection framework, in that, while protections are legally available to trafficking victims, there are limited opportunities for persons in similar situations who do not qualify as trafficked.

An important issue is how migration and border management and controls in Europe contribute to the increased vulnerability of migrants/refugees in transit and thereby also to increased risk of trafficking. The different resources available to migrants/refugees create different pathways and opportunities as well as risks and vulnerabilities. Being without money while in transit means being unable to pay for food and water, a place to stay, clothing and also for smugglers to facilitate onward travel. Many people in transit in Serbia at the time of writing are those who were without the resources to transit the country before the borders closed or pay smugglers to assist them once borders had closed.

As noted in our discussion of terminology and policy above, many challenge the privileging of "refugees" over "migrants" and the assumption that the former are, by definition, more vulnerable or entitled to protection than the latter. Nationality and citizenship are of the utmost importance in terms of protection opportunities for refugees as compared to migrants. Amongst migrants/refugees attempting to transit the Balkans and enter the EU, priority was given to nationalities perceived to be at higher risk and more like to qualify as refugees - i.e. Syrian, Iraqi and Afghani. This also translates into access to rights in the intermediate term. The prioritization of refugees (and some categories/nationalities of refugees) may render some migrants more vulnerable to other risks and exploitation including human trafficking. For example, one African woman was found ill and exhausted living outside of a Serbian refugee camp, having been denied access because her nationality precluded her being considered a refugee. Similarly, a group of North African boys who were attempting to reach the EU were pushed back across Balkan borders many times as they also did not, by nationality, qualify as refugees, which, arguably, put them at risk of abuse, violence and human trafficking on these journeys.

\section{Discussion: Barriers in identifying trafficked migrants and refugees}

Improving victim identification and, by extension, the anti-trafficking framework, requires an understanding of barriers and challenges to formal identification practice and processes. As we have argued elsewhere [8, 11], barriers to identification and assistance reveal a great deal about institutional responses in a country and how they may be improved. As importantly, understanding these types of barriers can also provide insight into decision making processes of people in precarious situations and their relative valuations of their assistance and protection opportunities. Identification of trafficking victims is not a passive, one-way process, in which social workers, police or others sort through and ascribe categorisations to individuals or groups. Rather, it is closely bound up with whether those being identified assess it as beneficial to them [8, 9]. Even under the best of circumstances, identification of trafficking victims is complicated [7, 24, 34]. Identifying trafficking victims amongst migrants and refugees introduces additional layers of complexity and complication. 
One significant challenge in identifying trafficking victims along the Balkan route was the very high number of people that moved along this corridor in a very short time span. Assessing vulnerability in general in this setting, let alone specific aspects that indicate human trafficking, was an enormous, if not impossible, task. These specific and extraordinary circumstances, which included significant language and cultural barriers in this fast moving situation, had direct consequences for how NGO staff could work to identify vulnerability, both in general and for trafficking, in that they relied on simple and more "visible" indicators - for instance, pregnant women, women and girls traveling on their own, unaccompanied children or women with children, the elderly (see also [21], pp. 55-56). While staff generally did feel that these were particularly vulnerable groups, they also recognised that it was not a sufficiently developed or adequately nuanced framework for identifying possible trafficking victims and others who were in particular need of assistance or protection.

Visible risk is also an unreliable indicator. For instance, unaccompanied minors are, in theory, a visibly identifiable group with obvious risks and vulnerability to exploitation due to their age, maturity and unaccompanied status. But, as one service provider noted of her work with vulnerable children during the crisis, some older children and youth may not be easily recognizable as children. By virtue of what they have endured as migrants/refugees, they may appear and behave older than they are and, as such, be perceived as adults, meaning that their risk of trafficking exploitation may be overlooked.

Many assumptions about risk and vulnerability are highly gendered, with risk and vulnerability viewed as female traits and strength and resilience as male traits [32, 42]. Migrant/refugee women and girls are, therefore, commonly perceived as more vulnerable than men and boys in most migration/refugee settings. There is indeed substantial evidence that some vulnerability (including sexual and physical violence) may be a direct function of being a woman and or a girl [2]. Nonetheless, the perpetration of sexual violence against men and boys in conflict situations is increasingly being studied $[4,31]$, including amongst males originating from countries commonly represented on the Balkan route like Syria, Afghanistan and Iraq [1, 14]. NGOs in the Balkans documented several cases of men and boys being exposed to sexual and physical violence and human trafficking. Boys in particular are too often seen through the lens of their sex/gender (i.e. male and, thus, strong and invulnerable) rather than their age/ maturity (i.e. as a child with rights to protection). For instance, whereas it would raise concerns if a young woman or girl was traveling alone along the Balkan route, young men and older boys in the same situation seemingly did not raise the same level concern or need for interventions from some frontline responders.

The identification of victims among migrants/refugees was not merely an issue of NGO staff being sufficiently attentive to different patterns of vulnerability but was also complicated by an unwillingness among some migrants/refugees to share their experiences. NGO staff found it particularly sensitive and difficult to approach the issue of sexual violence with both female and male migrants/refugees, and perhaps especially with men and boys. It is generally assumed that sexual violence is underreported and particularly so among males, due to shame, stigma and ideas about victimhood being incompatible with masculinity and akin to emasculation [38]. This was mirrored in the experiences of NGO staff, who had observed that, in some cases, men and boys were 
mocked by others for apparently having been sexually assaulted and that the men and boys in question were unwilling to share any information about what had happened.

Of note are cases when people are involved in unlawful activities as part of their trafficking exploitation, as it is not always recognised that someone who may have broken the law may at the same time be a victim of trafficking. Examples of this include people who have been coerced into taking part in smuggling, for instance as translators or recruiters. Recognising that such acts may sometimes be the result of trafficking means the difference between the person being punished or whether a more complex background for their actions is taken into account. The Council of Europe Convention on Action against Trafficking in Human Beings requires State Parties to implement legislation providing for the possibilityof non-punishment when involvement in unlawful activities has been compelled [15]. At the same time, it should be noted that this is only a possibility, and that many complex legal requirements may apply [41].

Being identified as a trafficking victim does not always align with people's interests or identity. The general human trafficking literature points to a number of factors, including not identifying with the victim of trafficking role, or with a victim identity in general $[8,26]$. A further complicating factor in the "refugee crisis" was that (possible) trafficked migrants/refugees did not want to be identified as trafficking victims because formal identification in a transit country like Serbia was not in their long-term interests and trafficking-specific assistance not what they wanted or needed in their life at that moment in time. That is, being formally identified as a victim of human trafficking in Serbia affords various rights and protections, including the right to temporarily stay in the country and to receive assistance and protection. However, formal identification also means staying in Serbia or even returning home if no residency permit is granted in the longer term. As such, this protection conflicts with the migrants'/refugees' main objective, which is to arrive safely in the EU and establish a life there. One social worker described how migrants/refugees were often under some pressure from family and community members as well who had as a personal goal to resettle in the EU. One study found that a sizable proportion of Syrian refugees along the Balkan route were following family or friends who had previously travelled the route (serving as "trailblazers") and had a set destination [29]. The unpredictability and rapid changes of border and migration management may also enhance the urgency to move on, for fear of being trapped within closed or closing borders.

\section{Conclusion}

It is challenging, even under the best of circumstances, to identify trafficking victims, for a wide range of practical, conceptual and institutional reasons. But in the situation encountered in Serbia, and in other countries in the Balkans and along the Mediterranean, the massive and rapid transit movement of migrants/refugees brought with it some very specific barriers and obstacles. One such barrier was the extraordinarily high number of deeply vulnerable migrants/refugees from many different countries and cultural backgrounds, speaking many different languages who passed through Serbia along the Balkan route in a very short period of time. Opportunities and entry points for 
interacting with these migrants/refugees in this transit setting and in ways that would lead to victim identification were heavily constrained.

Setting up appropriate and effective human trafficking screening mechanisms or identifying particular vulnerabilities of human are enormous tasks in this fluid and everchanging transit setting. Typical indicators and signals of trafficking risk are of variable relevance in identifying trafficked migrants/refugees. Further complicating identification efforts are gendered as well as nationality- and ethnicity-based assumptions about who is (and is not) vulnerable to human trafficking amongst migrants/refugees. Moreover, trafficking exploitation takes new forms and affects a diverse set of victims (of varying profiles) in this migration/refugee context, which means frontline responders must act and react to these on-going changes in their efforts to identify trafficking victims amongst migrants/refugees. And even when able to formally identify trafficking victims, this designation may be against the migrant's/refugee's self-interest, when their goal is to reach the EU and where the involvement of authorities hinders this goal.

We started out with the question of whether and to what extent the anti-trafficking framework is effective in offering protection to trafficked persons within a migrant/ refugee population in a mass migration setting, or whether other instruments and frameworks are better suited to meet these needs. What we found was that the antitrafficking framework is sometimes difficult to apply, does not always fit well with peoples' experiences and protections on offer may not be suitable for or wanted by those who are eligible, at least in the transit setting and at that moment of time. For instance, when assistance to trafficking victims does not sufficiently align with what trafficked migrants/refugees want and need, they may find it more useful to access the (albeit less comprehensive) support and services available through asylum systems and procedures (temporary stay, humanitarian assistance) as an interim measure on their onward journey/flight. Services for refugees may more easily dovetail with what they are looking for in the short-term and further facilitate their onward migration/flight to the EU. Thus, in some cases, the asylum and humanitarian architecture may be better equipped to meet the needs of trafficked migrants/refugees, at least in some settings and at some stages of their migrant/flight.

Questions then arise as to when and how the human trafficking lens may be of relevance in meeting the urgent as well as long-term needs of trafficked migrants/ refugees in transit in Serbia. And as noted in our discussion above of criticism raised about the conceptual separation between different groups in terms of their 'deservedness' to assistance and support or assumptions about relative vulnerability ('migrants' vs 'refugees', 'victims of trafficking' vs. exploited and vulnerable persons in general), administrative labels and separation between institutional frameworks do not easily fit with the complexities involved in responding to mixed migration, either as a matter of principle or as a matter of practical application. However, and in our view, a trafficking perspective offers an important means of viewing, understanding and responding to the experiences and needs of trafficked migrants/refugees, individuals who have suffered complex injustice and injury. As also noted above, human trafficking legislation considers the possibility of non-punishment in cases where a person has broken the law as a result of their trafficking, which is important not only in terms of how cases are pursued in the justice system, but which also highlights for actors not within the justice system that someone who might otherwise be treated as a suspect can at the same time be a victim of serious crime. In addition, the identification of trafficking victims 
amongst migrants and refugees is also often one of very few sources (or even the only source) of information about human trafficking in an ongoing conflict or war situation, although collecting such data in transit settings brings with it many of the same challenges that we have described for practical identification work. Yet, with security concerns and lack of or limited numbers of humanitarian actors "on the ground" (or humanitarian actors being overwhelmed with other issues and needs), options for identification can be extremely limited and information may only be collected at a later stage, in spite of this information being crucial to inform interventions.

While there are fundamental challenges to the anti-trafficking framework, it is important to consider what, realistically, are alternatives in terms of the categorisations that take place within migration management regimes. Furthermore, the particular lens of human trafficking can, if applied well, draw attention to and address forms of vulnerability that may otherwise go unrecognised and unaddressed. In our view, the discussion of human trafficking in a mass migration/refugee setting needs to be reoriented and expanded toward greater inclusivity, to also include a more comprehensive approach to victim protection and to understand and address trafficking risk and vulnerability. There is a particular legal and regulatory framework in place for victim protection in the anti-trafficking field and trafficked persons have rights that, while imperfect, can and should be leveraged to greater effect. But this should all be done with careful attention to and coordination with other protection architecture, like humanitarian responses and refugee frameworks. Once trafficking victims are identified (granted, a vexing and complex task), the next step is to guide trafficked migrants and refugees to access the rights and services that meet and address their specific and urgent vulnerabilities in ways that support their ability to move on past their exploitation.

Finally, in the cases we have analysed front line staff described a fluidity between what might clearly be classified as trafficking and other forms of exploitation, as well as between being vulnerable to trafficking and being vulnerable in general. There are many hardships and reported abuses suffered by migrants/refugees that are not covered by the trafficking definition and, by implication, protections available to trafficking victims. This highlights the importance of leveraging all available protection frameworks in meeting the immediate and long term needs of these trafficked and nontrafficked migrants and refugees.

Open Access This article is distributed under the terms of the Creative Commons Attribution 4.0 International License (http://creativecommons.org/licenses/by/4.0/), which permits unrestricted use, distribution, and reproduction in any medium, provided you give appropriate credit to the original author(s) and the source, provide a link to the Creative Commons license, and indicate if changes were made.

\section{References}

1. Akhtar, R. (2019). The neglected boys of war. Trapped in a vicious cycle of slavery and sexual abuse. Journal of Trafficking and Human Exploitation, 3(February), 179-206.

2. Amnesty International. (2016). "I want a safe place". Refugee women from Syria uprooted and unprotected in Lebanon. Retrieved from London: https:/www.amnesty.org/en/documents/mde18/3210 /2016/en/. Accessed 19 Jan 2018.

3. Anderson, B., \& Andrijasevic, R. (2008). Sex, slaves and citizens: The politics of anti-trafficking. Soundings, 40, 135-145. 
4. Apperley, H. (2015). Hidden victims: A call to action on sexual violence against men in conflict. Medicine, conflict and survival, 31(2), 92-99.

5. Bakewell, O. (2008). Research beyond the categories: The importance of policy irrelevant research into forced migration. Journal of Refugee Studies, 21(4), 432-453.

6. Bechev, D. (2016). Europe's refugee crisis and the Balkans. Retrieved from http://www.sharqforum. org/2016/06/08/europes-refugee-crisis-and-the-balkans/. Accessed 19 Jan 2018.

7. Bjelland, H. F. (2016). Identifying human trafficking in Norway: A register-based study of cases, outcomes and police practices. European Journal of Criminology, 14(5), 522-542.

8. Brunovskis, A., \& Surtees, R. (2007). Leaving the past behind: When victims of trafficking decline assistance. Oslo: Fafo.

9. Brunovskis, A., Surtees, R. (2012). Out of sight? Approaches and challenges in the identification of trafficked persons (Vol. 2012:28). Oslo: Fafo.

10. Brunovskis, A., \& Surtees, R. (2017). Vulnerability and exploitation along the Balkan route: Identifying victims of human trafficking in Serbia (Vol. 2017:12). Oslo: Fafo.

11. Brunovskis, A., \& Surtees, R. (2019). Identification of trafficking victims in Europe and the former Soviet Union. In S. Poucki \& J. Clark (Eds.), The SAGE Handbook of Human Trafficking and Modern Slavery (pp. 339-359): SAGE.

12. Carling, J. (2015). Refugees are also migrants. And all migrants matter. Retrieved from http://bordercriminologies.law.ox.ac.uk/refugees-are-also-migrants/. Accessed 19 Jan 2018.

13. Carling, J., Gallagher, A. T., \& Horwood, C. (2015). Beyond Definitions-Global migration and the smuggling-trafficking nexus. In: Nairobi: Danish Refugee Council.

14. Chynoweth, S. (2017). 'We keep it in our heart'. Sexual Violence against men and boys in the Syria crisis. Switzerland: Geneva: UNHCR.

15. Council of Europe Convention on Action Against Trafficking in Human Beings, (2005).

16. Crawley, H., \& Skleparis, D. (2018). Refugees, migrants, neither, both: Categorical fetishism and the politics of bounding in Europe's 'migration crisis'. Journal of Ethnic and Migration Studies, 44(1), 4864.

17. Deutsche Welle. (2015). Libya and human trafficking across the Mediterranean. Deutche Welle. Retrieved from http://www.dw.com/en/libya-and-human-trafficking-across-the-mediterranean/av18467450. Accessed 19 Jan 2018.

18. Deutsche Welle. (2016). Stranded in Serbia - refugees in limbo. Deutche Welle.

19. Erdal, M. B., \& Oeppen, C. (2017). Forced to leave? The discursive and analytical significance of describing migration as forced and voluntary. Journal of Ethnic and Migration Studies, 1-18.

20. European Council. (2016). EU-Turkey statement, 18 march 2016 [press release]. Retrieved from http://www.consilium.europa.eu/en/press/press-releases/2016/03/18/eu-turkey-statement/. Accessed 19 Jan 2018.

21. Forin, R., \& Healey, C. (2018). Trafficking along migration routes to Europe. Bridging the gap between migration, asylum and anti-trafficking. Austria: Vienna: ICMPD.

22. Frontex. (2016). Western Balkans. Retrieved from http://frontex.europa.eu/trends-and-routes/westernbalkan-route/. Accessed 19 Jan 2018.

23. Greene, J. M., Ennett, S. T., \& Ringwalt, C. L. (1999). Prevalence and correlates of survival sex among runaway and homeless youth. American Journal of Public Health, 89(9), 1406-1409.

24. Hoyle, C., Bosworth, M., \& Dempsey, M. (2011). Labelling the victims of sex trafficking: Exploring the borderland between rhetoric and reality. Social \& Legal Studies, 20(3), 313-329.

25. ITV. (2015). PM blames Calais crisis on 'swarm' of migrants ITV. Retrieved from http://www.itv. com/news/update/2015-07-30/pm-a-swarm-of-migrants-want-to-come-to-britain/. Accessed 19 Jan 2018.

26. Jacobsen, C. M., \& Skilbrei, M.-L. (2010). 'Reproachable Victims'? Representations and selfrepresentations of Russian women involved in transnational prostitution. Ethnos, 75(2), 190-212. https://doi.org/10.1080/00141841003764013.

27. La Strada / Open Gate. (2016). Social Protection of Refugees in Macedonia. Skopje, Macedonia: GIZ and La Strada/Open Gate Macedonia.

28. Malone, B. (2015). Why Al Jazeera will not say Mediterranean 'migrants'. Retrieved from http://www. aljazeera.com/blogs/editors-blog/2015/08/al-jazeera-mediterranean-migrants-150820082226309.html. Accessed 19 Jan 2018.

29. Mandic, D. (2017). Trafficking and Syrian refugee smuggling: Evidence from the Balkan route. 5(22), 28-38. doi:https://doi.org/10.17645/si.v5i2.917.

30. McQuade, A. (2015). Migrant crisis: smuggling or trafficking? Politicians don't seem to know The Guardian. Retrieved from https://www.theguardian.com/global-development/2015/apr/22/migrant-crisissmuggling-trafficking-politicians-dont-seem-to-know. Accessed 19 Jan 2018. 
31. Meger, S. (2018). The political economy of sexual violence against men and boys in armed conflict. In Sexual violence against men in global politics (pp. 118-132). Routledge.

32. Paasche, E., \& Skilbrei, M.-L. (2017). Gendered vulnerability and return migration. TEMIDA, 20(1), 149-166.

33. Physicians for Human Rights. (2010). Hostages, Torture, and Rape in the Sinai Desert: A PHR-Israel update about recently arriving asylum seekers. Retrieved from http://reliefweb.int/report/eritrea/hostagestorture-and-rape-sinai-desert-phr-israel-update-about-recently-arriving. Accessed 19 Jan 2018.

34. Pickering, S., \& Ham, J. (2014). Hot pants at the border sorting sex work from trafficking. British Journal of Criminology, 54(1), 2-19.

35. Reisen, M. v., \& Rijken, C. (2015). Sinai trafficking: Origin and definition of a new form of human trafficking. Social Inclusion, 3(1), 113-124. https://doi.org/10.17645/si.v3i1.180.

36. Samarasinghe, V. (2003). Confronting globalization in anti-trafficking strategies in Asia. Brown Journal of World Affairs, 10(1), 91-104.

37. Schmidt, M. E., \& Chan, S. (2016). NATO will send ships to Aegean Sea to deter human trafficking. The New York Times. Retrieved from https:/www.nytimes.com/2016/02/12/world/europe/nato-aegeanmigrant-crisis.html? r=2. Accessed 19 Jan 2018.

38. Sivakumaran, S. (2007). Sexual violence against men in armed conflict. European journal of international law, 18(2), 253-276.

39. Snajdr, E. (2013). Beneath the master narrative: Human trafficking, myths of sexual slavery and ethnographic realities. Dialectical Anthropology, 37(2), 229-256.

40. Sputnik International. (2016). Over 900,000 passed through Serbia since refugee crisis began - foreign minister. Sputnik International. Retrieved from https://sputniknews.com/europe/201612081048317198serbia-refugees-crisis/. Accessed 19 Jan 2018.

41. Stoyanova, V. (2015). Human Trafficking and Slavery Reconsidered. Conceptual Limits and States' Positive Obligations. Juridiska fakulteten, Lund.

42. Surtees, R. (2008). Trafficked men as unwilling victims. St Antony's International Review, 4(1), 16-36.

43. The Guardian. (2015). Hungary closes border to refugees as Turkey questions EU deal to stem crisis. The Guardian. Retrieved from https:/www.theguardian.com/world/2015/oct/17/hungary-closes-border-torefugees-as-turkey-questions-eu-deal-to-stem-crisis. Accessed 19 Jan 2018.

44. The Sun. (2015). They think it's all Dover. The Sun. Retrieved from https://www.thesun.co. uk/archives/news/126977/they-think-its-all-dover/. Accessed 19 Jan 2018.

45. UNHCR. (2017). Inter-agency operational update Serbia November 2017. Retrieved from https://reliefweb.int/sites/reliefweb.int/files/resources/61412.pdf. Accessed 19 Jan 2018.

46. UNHCR. (2018). Mediterranean situation. Retrieved from https://data2.unhcr. org/en/situations/mediterranean. Accessed 11 Apr 2018.

47. Protocol to prevent, suppress and punish trafficking in persons, especially women and children, supplementing the United Nations convention against transnational organized crime, (2000).

48. Vonberg, J. (2015). Al Jazeera will not say Mediterranean 'migrants', but we should. Retrieved from http://www.migrantsrights.org.uk/migration-pulse/2015/al-jazeera-will-not-say-mediterranean-migrantswe-should. Accessed 19 Jan 2018.

49. Weitzer, R. (2007). The social construction of sex trafficking: Ideology and institutionalization of a moral crusade. Politics and Society, 35(3), 447-475. https://doi.org/10.1177/0032329207304319.

Publisher's note Springer Nature remains neutral with regard to jurisdictional claims in published maps and institutional affiliations. 